\section{Endoscopically and Histologically Documented Gastrointestinal Lesions in an Adult Patient with Henoch-Schönlein Purpura}

Henoch-Schönlein purpura (HSP), presenting with severe abdominal pain and gastrointestinal hemorrhage without other common symptoms, defies diagnosis due to its unspecific roentgenologic findings $(1,2)$ and the limited endoscopic data associated with it. We present here a life-threatening case of the disease.

A 62-year-old Japanese male complained of intermittent cramping pain over the entire abdomen, hematemesis, and massive hematochezia, developing shock. He was shown on colonoscopy to have a blood-oozing aphthoid ulcer on the prolapsing ileocecal valve (Figure 1). The ulcer was soon reduced. It was no longer detectable several days later, but other evanescent ulcers were observed in stead (Figure 2). Transitory punctate and longitudinal hemorrhagic erosions and petechiae were present in virtually the entire upper gastrointestinal tract. Biopsy of the colonic lesions demonstrated wall and perivascular granulocytes, which are histologic criteria for the classification of HSP (3). The patient then developed palpable

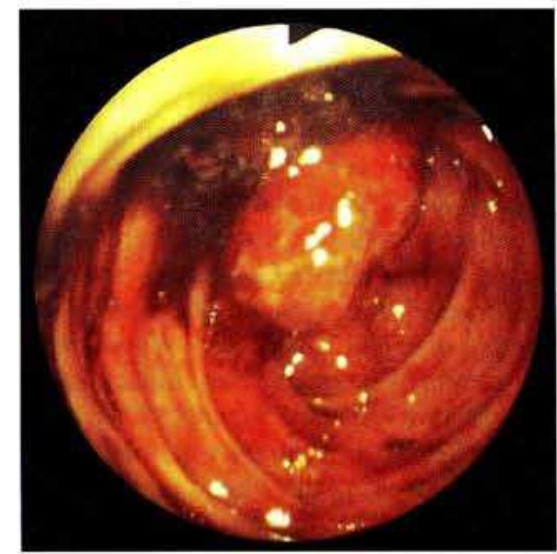

Figure 1:

Colonoscopic view of the prolapsing ileocecal valve, showing a starshaped aphthoid ulcer with oozing of blood on the upper lip. cutaneous purpura, arthralgia, proteinuria, and hematuria. A biopsy specimen from the fresh rash was interpreted as $\operatorname{IgA}$-associated leukocytoclastic vasculitis. He responded very well to the administration of glucocorticoids. 
This is the first case of HSP in which involvement of the ileocecal valve has been documented endoscopically and histologically. Though each gastrointestinal lesion per se is not pathognomonic, the subtle and protean nature of the lesions is considered to be characteristic, in contrast to the fulminant clinical features of the disease.

\section{K. Sasaki ${ }^{1}$, Y. Nukuda ${ }^{2}$, T. Masuda ${ }^{3}$, E. Sato $^{4}$}

${ }^{1}$ Department of Internal Medicine, National Health Insurance Shikama Hospital, Miyagi, Japan; ${ }^{2}$ First Department of Surgery and ${ }^{3}$ Second Department of Pathology, Tohoku University School of Medicine, Sendai, Miyagi, Japan; ${ }^{4}$ Second Department of Pathology, Kagoshima University School of Medicine, Kagoshima, Japan

\section{References}

1. Glasier CM, Siegel MJ, McAlister WH et al.: Henoch-Schönlein syndrome in children: gastrointestinal manifestations. Am J Roentgenol 1981; 136: 1081-1085.

2. Katz $S$, Borst M, Seekri $I$ et al.: Surgical evaluation of HenochSchönlein purpura: experience with 110 children. Arch Surg 1991; 126: 849-854.

3. Mills JA, Michel BA, Bloch DA et al.: The American College of Rheumatology 1990 criteria for the classification of Henoch-Schönlein purpura. Arthritis Rheum 1990; 33: 1114-1121.

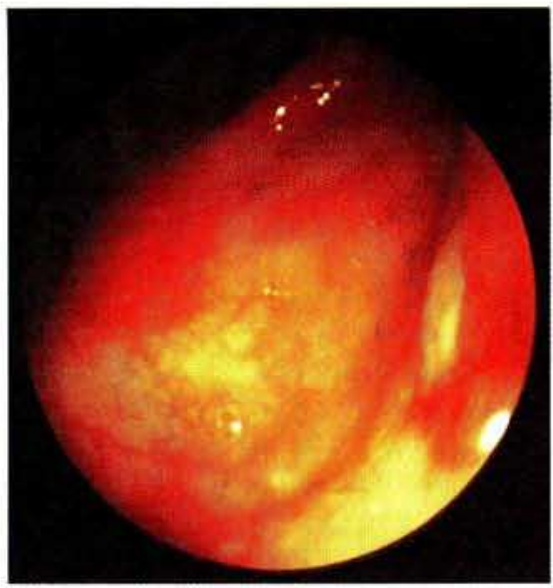

Figure 2:

Colonoscopic appearance of a punctate aphthoid ulcer on the lower lip of the ileocecal valve, which was not present one week earlier.

\section{Corresponding Author}

K. Sasaki, M.D., Department of Internal Medicine, The National Health Insurance Shikama Hospital, 26 Higashi, Machi, Shikama, Kami, Miyagi 981-41, Japan 